chest pain radiating to both arms and associated with sweating. The E.C.G. showed a sinus tachycardia with occasional supraventricular extrasystoles and an inferior infarct. Serial serum transaminases were raised. The next day she developed a rapid atria fibrillation for which she was digitalized However, the dysrhythmia persisted 18 hours and $10 \mathrm{mg}$ verapamil were given intravenously over a period of 20 seconds. Within 10 minutes, her cardiac rate had decreased from 180 per minute to 120 per minute. A tracing at this time showed sinus tachycardia with supraventricular extrasystoles. The patient remained in sinus rhythm and 24 hours later the rate was 90 per minute. No side effects were noted.

The second patient, aged 62, gave a twoyear history of infrequent attacks of paroxysmal tachycardia, which usually lasted 10 minutes only. On this occasion she developed severe central chest pain radiating to the left arm. This was preceded by palpitations. At the time of admission she was conscious but drowsy, her breathing shallow and spasmodic. She was ashen and sweating profusely.

The blood pressure was unrecordable. An E.C.G. showed a supraventricular tachycardia of 180 per minute with widespread severe ischaemic changes. $5 \mathrm{mg}$ of verapamil were given intravenously over a period of 10 seconds. After a short episode of asystole lasting about 10 seconds, sinus rhythm was restored at the rate of 60 per minute. The blood pressure became recordable at $50 / 20 \mathrm{~mm} \mathrm{Hg}$. The central venous pressure was monitored and $50 \mathrm{mg}$ phenoxybenzamine were given in $200 \mathrm{ml}$ of $5 \%$ dextrose over two hours. The patient also required intermittent positive pressure respiration which was maintained for 18 hours. Two hours after admission she was still drowsy, but peripheral pulses were palpable and the blood pressure was $105 / 60$ $\mathrm{mm} \mathrm{Hg}$. The next day she was conscious and alert, and no longer required cardiac monitoring. The serum glutamic oxaloacetic transaminase was raised at 270 S.F. units, confirming severe myocardial damage.

Both cases confirm the usefulness of verapamil as an antidysrhythmic drug, and the second demonstrates that verapamil will restore sinus rhythm in a patient with severe circulatory failure and cardiac ischaemic due to rapid supraventricular tachycardia with out worsening ventricular function or precipitating ventricular arrhymias.

I shoud like to thank Dr. J. G. Lewis who suggested using this drug.

-I am, etc.,

Edgware General Hospital,

J. R. MILnE

Edgware, Middx

SIR,-The antiarrhythmic properties of verapamil (Cordilox) are well established. It is reported to be a safe drug producing little adverse cardio-circulatory disturbance. Schamroth et al. (11 March, p. 660) treated 181 patients and none experienced any ill effect, though cardiac output and blood pressure were diminished in two patients already receiving digoxin and practolol.

A 70-year-old man presented with a supraventricular tachycardia of 160 beats per minute. He was already digitalized, having had a similar episode three years previously.
Practolol $20 \mathrm{mg}$ was given intravenously over period of 15 minutes. No alteration in cardiac rate of rhythm was produced, and the patient experienced no symptoms over the following 40 minutes. Verapamil $5 \mathrm{mg}$ was then given intravenously over five minutes. Ventricular rate fell to 100 beats per minute, with the appearance of atrial flutter with A-V block. Further ventricular slowing occurred, proceeding to complete ventricular asystole. External cardiac massage and intravenous isoprenaline were required for 10 minutes to maintain the circulation. The patient recovered fully and the supraventricular dysrhythmia persisted. Sinus rhythm was finally established following DC cardioversion.

A 6-month-old child had myocarditis with cardiac failure and a supraventricular tachycardia of $240 / \mathrm{min}$. The cardiac failure had responded to digoxin and frusemide. Eyeball pressure caused the dysrrhythmia to slow to $130 / \mathrm{min}$, but it rapidly reverted despite adequate dosage of epanutin or practolol. A verapamil bolus of $1.25 \mathrm{mg}$ intravenously produced no effect. A second dose given slowly after 15 minutes slowed the rate to $180 / \mathrm{min}$, but 10 minutes later ventricular asystole developed, which responded only after six minutes to external cardiac massage, intravenous isoprenaline and sodium bicarbinate, intracardiac calcium gluconate, and isoprenaline. We would therefore suggest caution in the use of verapami for supraventricular tachycardias after previous treatment with digoxin and practolol -We are, etc.

C. B. BOOTHBY

C. S. GARRARD D. Pickering

Departments of Cardiology and Paediatrics, Radcliffe Infirmary, Oxford

\section{G.M.C. Accounting}

SIR,-Last year I had an extraordinary brush with the General Medical Council, which threatened to erase my name from the Register because, said the council, it had not received my annual retention fee. I was very surprised by this because I had completed a banker's order and the sum in question had in fact been debited from my current account. Subsequently, the General Medical Council admitted to having received the fee and the threat to erase my name from the Register became inoperative.

Now I have just read the council's lates circular dated April 1972 in which they state that they are no longer disposed to recommend payment of the retention fee by banker's order as preferable to payment by cheque. If, as would appear to be the case from the circular, the council finds it difficult to keep track of fees paid by banker's order, the policy of asking doctors to pay by cheque is no doubt prudent; but it is surely bizarre that the council should find itself in this difficulty. Like many other people I pay dozens of subscriptions by banker's order, and the one to the G.M.C is the only one in my personal experience which has been the subject of confusion. I wonder whether other practitioners have had a similar experience.-I am, etc.,

Michael WOODRUFF attempts to return to or stay in medicine is a continually recurring theme. Besides the

SIR,-We should like to answer the points raised by Drs. D. L. Coppel and J. W. Dundee (25 March, p. 805). The triall was conducted on inpatients alone, and our recommendations for the use of ketamine in electroconvulsion therapy (E.C.T.) do not apply to outpatients, although we found that the recovery time following intravenous ketamine was not substantially longer than that for intravenous thiopentone. They are correct in assuming that suxamethonium in customary dosage was used as a relaxant.

Following intramuscular ketamine the recovery period was naturally somewhat longer, but we felt that this was outweighed by the fact that the induction of distraught, uncooperative, or agitated patients was made considerably easier and less unpleasant for both staff and patients.

Your correspondents draw attention to the possibility of ketamine delirium, but we had made it clear (12 February, p. 442) that in none of our patients was ketamine anaesthesia followed by hallucinations or other perceptual disorders. This corresponds with the experience of Orecchia et $a .^{2}$ and suggests that psychiatric patients receiving E.C.T. are less likely than others to become disturbed after ketamine anaesthesia. Likely explanations for this finding were advanced previously (12 February, p. 442).-We are, etc.,

Jonathan Davidson

Royal Edinburgh Hospital,

Edinburgh

COLIN BREWER

Queen Elizabeth and Midland Nerve Hospitals.

1 Brewer, C., Hereward, S., and Davidson, J., 2 British fournal of Prychiatry, 1972, in p-ess. M:nerva Anestesiologica, 1969, 35, 711 .

\section{Amantadine in Jakob-Creutzfeldt Disease}

SiR,-Dr. J. Braham's report (23 October 1971, p. 212) of benefit in Creutzfeldt-Jakob disease from the administration of amantadine is of great interest and deserves further trial in other patients. The occurrence of amyotrophy in many patients with that disease might suggest to some that amantadine also be tried in amyotrophic lateral sclerosis or motor neurone disease.

Between 1967 and 1970. I used amantadine in the experimental treatment of amyotrophic lateral sclerosis with no detectable alteration of the usual clinical course in 18 patients and distinct worsening in two patients. The latter improved somewhat when the amantadine was discontinued temporarily, worsened again when the amantadine was reinstituted, and improved somewhat when the amantadine was finally stopped. I concluded therefore that amantadine is of no value in the treatment of motor neurone disease and in fact might be harmful in some cases.-I am, etc.,

Forbes H. NORRIS, JUN. Institute of Neurological Sciences, University of the Pacific,
San Francisco, Calif., U.S.A.

\section{Health Service Woman-power}

